\title{
Commentary: Differential Signaling Mediated by ApoE2, ApoE3, and ApoE4 in Human Neurons Parallels Alzheimer's Disease Risk
}

\author{
Patrycja Dzianok* and Ewa Kublik \\ Laboratory of Emotions Neurobiology, Nencki Institute of Experimental Biology PAS, Warsaw, Poland
}

Keywords: Alzheimer's disease, APOE, neurodegeneration, synapse, risk-genes

\section{A commentary on}

Differential Signaling Mediated by ApoE2, ApoE3, and ApoE4 in Human Neurons Parallels Alzheimer's Disease Risk

by Huang, Y. A., Zhou, B., Nabet, A. M., Wernig, M., and Südhof, T. C. (2019). J. Neurosci. 39, 7408-7427. doi: 10.1523/JNEUROSCI.2994-18.2019

\section{OPEN ACCESS}

Edited by:

Robert Petersen,

Central Michigan University,

United States

Reviewed by:

Boon-Seng Wong,

Singapore Institute of

Technology, Singapore

${ }^{*}$ Correspondence:

Patrycja Dzianok

p.dzianok@nencki.edu.pl

Received: 28 February 2020

Accepted: 15 April 2020

Published: 08 May 2020

Citation:

Dzianok P and Kublik E (2020) Commentary: Differential Signaling Mediated by ApoE2, ApoE3, and ApoE4 in Human Neurons Parallels

Alzheimer's Disease Risk

Front. Aging Neurosci. 12:127.

doi: 10.3389/fnagi.2020.00127
Alzheimer's disease $(\mathrm{AD})$ is a neurodegenerative condition that inevitably impairs cognitive functions and influences a patient's behavior, mood, and self-reliance. Due to demographic changes, $\mathrm{AD}$ and other age-associated diseases have become increasingly common and burdensome for families, as well as entire societies. It is extremely important that we learn more about specific mechanisms that can be linked to the development of the disease. The main symptoms of AD, observed in the central nervous system, are brain atrophy and loss of neurons and synapses. They are believed to result from excessive aggregation of tau protein and amyloid plaques (composed of $B$-amyloid). However, neither the initial cause nor the detailed chain of events that lead to this type of neurodegeneration are known. No deterministic genes were identified for late-onset Alzheimer's disease (LOAD), but several risk genes seem to be involved in its pathogenesis. The gene coding apolipoprotein $\mathrm{E}(A P O E)$ is the best-known and has the strongest association with $\mathrm{AD}$ development. $\mathrm{AD}$ probability decreases in carriers of the e 2 variant of the APOE gene (APOE-e2), whereas APOE-e4 is believed to be a strong risk factor (Strittmatter et al., 1993) and is associated with overall cognitive impairment and synapse loss (see review by Selkoe, 2002).

Few hypotheses have been proposed in the literature explaining possible mechanisms by which $A P O E$ could affect the brain and promote $\mathrm{AD}$. ApoE in the brain is mostly expressed by astrocytes and microglia and is thought to be involved in the metabolism and clearance of lipoproteins (see Fernandez et al., 2019 for review). Astrocytes play a vital role in the internalization and degradation of extracellular beta-amyloid $(A \beta)$, the component which forms plaques that are believed to be involved in AD neurodegeneration (Serrano-Pozo et al., 2011; Ries and Sastre, 2016, see also review by Haass and Selkoe, 2017; Fernandez et al., 2019). The APOE-e4 variant was shown to be least effective in degradation of $\mathrm{A} \beta$ (Castellano et al., 2012).

Another hypothesis points to the fact that ApoE variants have different binding properties (Calandra et al., 2011) to the receptors that regulate intracellular signaling (Ohkubo et al., 2001; Qiu et al., 2004). This hypothesis was first addressed by Huang et al. (2017) and again in a replication and control study published last year in the Journal of Neuroscience (Huang et al., 2019). Their research was conducted on stem cell-derived human neurons cultured without glial cells. Results of the experiments (Huang et al., 2019) showed that even in the absence of glial cells ApoE strongly and diversely influenced signal transduction cascades in neurons, which led to intensification of 
amyloid precursor protein (APP) synthesis and, at the same time, to the formation of new synapses. The study revealed the synaptic paradox of the $A P O E$-related risk of AD: surprisingly, it was $A P O E-\mathrm{e}$, the gene variant that is linked to the highest risk of $\mathrm{AD}$, that was most efficient in stimulating MAP signaling and in enhancing synaptogenesis.

The question arises: how is it possible to link these celllevel studies with the same ranking $(A P O E-\mathrm{e} 4>A P O E-\mathrm{e} 3>$ $A P O E$-e2) of negative impact on human brain function in $\mathrm{AD}$. Results indicating enhanced APP synthesis are in agreement with studies showing higher levels of $A \beta$ in brains of $A P O E$-e 4 carriers, examined post-mortem (Shinohara et al., 2013), as well as in vivo studies using positron emission tomography (see review of Jack and Kepe, 2013). However, a reported APOE-e4-related increase in synapse formation contradicted numerous findings indicating the highest loss of synapses and severity of cognitive decline in APOE-e4 carriers (Terry et al., 1991; Selkoe, 2002; Scheff et al., 2006; Purro et al., 2012; Chen et al., 2018). It appears that the link between $A P O E$ isoforms and neuronal and synaptic dysfunction observed in $\mathrm{AD}$ comprises multiple, seemingly contradictory, mechanisms. Huang et al. (2019), and previously Lin et al. (2018), showed an APOE-e4 related increase in the number of synapses in isolated neurons. On the other hand in vivo research has demonstrated strong evidence of synapse loss related to memory and cognitive impairment, which characterize dementia and neurodegeneration. The direct effect of $A P O E-\mathrm{e} 4$ on neurons can be modulated by the interplay of many factors, including the activity of glial cells (mainly astrocytes and microglia) and other risk-genes. Moreover, it was shown that neurons need astrocytes and microglia to eliminate redundant synapses (Lee and Chung, 2019). Maintaining proper synapse number is a crucial process in learning and memory and thus any changes may disrupt the cells' homeostasis and lead to neurodegenerative diseases like AD. APOE-e4 was shown to inhibit synaptic pruning, realized by astrocyte phagocytosis, whereas $A P O E$-e2 promoted it Chung et al. (2016). APOE has a strong impact on lipoprotein (and cholesterol) homeostasis and synaptic stability maintenance, with $A P O E$-e4 having the most negative impact on the brain. APOEe4 limits the astrocytes' ability to recycle and clear extracellular cholesterol (Fernandez et al., 2019) and leads to its accumulation and an increase of $\mathrm{A} \beta$ (Strittmatter et al., 1993) related to

\section{REFERENCES}

Calandra, S., Tarugi, P., Speedy, H. E., Dean, A. F., Bertolini, S., and Shoulders, C. C. (2011). Mechanisms and genetic determinants regulating sterol absorption, circulating LDL levels, and sterol elimination: implications for classification and disease risk. J. Lipid Res. 52, 1885-1926. doi: 10.1194/jlr.R017855

Castellano, J. M., Kim, J., Stewart, F. R., Jiang, H., DeMattos, R. B., Patterson, B. W., et al. (2012). Human apoE isoforms differentially regulate brain amyloid- $\beta$ peptide clearance. Sci. Transl. Med. 3:ra57. doi: 10.1126/scitranslmed.3002156

Chen, M. K., Mecca, A. P., Naganawa, M., Finnema, S. J., Toyonaga., T., Lin, S. -F et al. (2018). Assessing synaptic density in alzheimer disease with synaptic vesicle glycoprotein 2A positron emission tomographic imaging. JAMA Neurol. 75, 1215-1224. doi: 10.1001/jamaneurol.2018.1836

Chung, W. S., Verghese, P. B., Chakraborty, C., Joung, J., Hyman, B. T., Ulrich, J. D., et al. (2016). Novel allele-dependent role for APOE in controlling the rate of synaptic dysfunction (Purro et al., 2012). Human astrocytes with $A P O E-$ e4 showed accumulation of cholesterol and could not efficiently fulfill their role related to clearance of $\mathrm{A} \beta$ (Lin et al., 2018).

Perhaps it is the initial higher number of synapses and APP in neurons with $A P O E$-e4 that leads to an increase in toxic $\mathrm{A} \beta$ forms and impairs astrocytes' function, which can initiate the whole cascade of changes related to later loss of synapses and cognitive functions. It may indicate that, in the brains of APOE-e4 carriers, $\mathrm{AD}$ risks begin to accumulate from early developmental stages when too many synapses are formed and not enough of them are pruned (Chung et al., 2016; Lin et al., 2018; Huang et al., 2019). Although, the APOE-e4 risk related to loss of cognitive functions is predominant for persons older than 50 years of age, people homozygous for APOE-e4 may experience the risk much earlier, just after 40 years of age (Liu et al., 2010). Other studies point out that $A P O E$-e4 could affect the brain even earlier, changing its structure, function and neurochemistry (see DiBattista et al., 2016 for review). APOE-e4 young carriers perform equally well or even much better in a variety of cognitive tasks compared to non-carriers (Mondadori et al., 2007; Jochemsen et al., 2012; DiBattista et al., 2016). The effect is tried to be explained by antagonistic pleiotropy hypothesis: some genes may enhance fitness early in life but act adversely in elderly. They are still favored by natural selection since the survival of the species depends on young individuals (Tuminello and Han, 2011; DiBattista et al., 2016). Understanding the specific influence of $A P O E$-e4 on neuronal signaling pathways throughout the lifespan may help us to identify early biomarkers and target therapy against $\mathrm{AD}$ in the future.

\section{AUTHOR CONTRIBUTIONS}

PD wrote the first draft. EK critically edited and improved the manuscript. PD and EK read and approved the final version of the manuscript.

\section{FUNDING}

This work was supported by a grant from the National Science Centre in Poland 2018/31/N/HS6/03551. synapse pruning by astrocytes. Proc. Natl. Acad. Sci. U.S.A. 113, 10186-10191. doi: 10.1073/pnas.1609896113

DiBattista, A. M., Heinsinger, N. M., and Rebeck, G. W. (2016). Alzheimer's Disease genetic risk factor APOE- $\varepsilon 4$ also affects normal brain function. Curr. Alzheimer Res. 13, 1200-1207. doi: 10.2174/15672050136661604011 15127

Fernandez, C. G., Hamby, M. E., McReynolds, M. L., and Ray, W. J. (2019). The role of APOE4 in disrupting the homeostatic functions of astrocytes and microglia in aging and Alzheimer's Disease. Front. Aging Neurosci. 11:14. doi: $10.3389 /$ fnagi.2019.00014

Haass, C., and Selkoe, D. J. (2017). Soluble protein oligomers in neurodegeneration: lessons from the Alzheimer's amyloid beta-peptide. Nat. Rev. Mol. Cell Biol. 8, 101-112. doi: 10.1038/nrm2101

Huang, Y. A., Zhou, B., Nabet, A. M., Wernig, M., and Südhof, T. C. (2019). Differential signaling mediated by ApoE2, ApoE3, and ApoE4 in 
human neurons parallels Alzheimer's Disease risk. J. Neurosci. 39, 7408-7427. doi: 10.1523/JNEUROSCI.2994-18.2019

Huang, Y. A., Zhou, B., Wernig, M., and Südhof, T. C. (2017). ApoE2, ApoE3, and ApoE4 differentially stimulate APP transcription and abeta secretion. Cell 168, 427-441. doi: 10.1016/j.cell.2016.12.044

Jack, C. R. Jr., Barrio, J. R., and Kepe, V. (2013). Cerebral amyloid PET imaging in Alzheimer's disease. Acta Neuropathol. 126, 643-657. doi: $10.1007 / \mathrm{s} 00401-013-1185-7$

Jochemsen, H. M., Muller, M., van der Graaf, Y., and Geerlings, M. I. (2012). APOE epsilon4 differentially influences change in memory performance depending on age. The SMART-MR study. Neurobiol. Aging 33, 832 e15-22. doi: 10.1016/j.neurobiolaging.2011.07.016

Lee, E., and Chung, W. S. (2019). Glial control of synapse number in healthy and diseased brain. Front. Cell Neurosci. 13:42. doi: 10.3389/fncel.2019.00042

Lin, Y. T., Seo, J., Gao, F., Feldman, H. M., Wen, H. L., Penney, J., et al. (2018). APOE4 causes widespread molecular and cellular alterations associated with Alzheimer's Disease phenotypes in human iPSC-derived brain cell types. Neuron 98, 1141-1154. doi: 10.1016/j.neuron.2018.05.008

Liu, F., Pardo, L. M., Schuur, M., Sanchez-Juan, P., Isaacs, A., Sleegers, K., et al. (2010). The apolipoprotein $\mathrm{E}$ gene and its age-specific effects on cognitive function. Neurobiol. Aging. 1831-3. doi: 10.1016/j.neurobiolaging.2008. 09.015

Mondadori, C. R., de Quervain, D. J., Buchmann, A., Mustovic, H., Wollmer, M. A., Schmidt, C. F., et al. (2007). Better memory and neural efficiency in young apolipoprotein E epsilon4 carriers. Cereb Cortex. 17, 1934-1947. doi: $10.1093 /$ cercor/bhl103

Ohkubo, N., Mitsuda, N., Tamatani, M., Yamaguchi, A., Lee, Y. D., Ogihara, T., et al. (2001). Apolipoprotein E4 stimulates cAMP response element-binding protein transcriptional activity through the extracellular signal-regulated kinase pathway. J. Biol. Chem. 276, 3046-3053. doi: 10.1074/jbc.M0050 70200

Purro, S. A., Dickins, E. M., and Salinas, P. C. (2012). The secreted Wnt antagonist Dickkopf-1 is required for amyloid $\beta$-mediated synaptic loss. J. Neurosci. 32, 3492-3498. doi: 10.1523/JNEUROSCI.4562-11.2012

Qiu, Z., Hyman, B. T., and Rebeck, G. W. (2004). Apolipoprotein E receptors mediate neurite outgrowth through activation of p44/42 mitogen-activated protein kinase in primary neurons. J. Biol. Chem. 279, 34948-34956. doi: $10.1074 /$ jbc.M401055200
Ries, M., and Sastre, M. (2016). Mechanisms of A $\beta$ clearance and degradation by glial cells. Front. Aging Neurosci. 8:160. doi: 10.3389/fnagi.2016.00160

Scheff, S. W., Price, D. A., Schmitt, F. A., and Mufson, E. J. (2006). Hippocampal synaptic loss in early Alzheimer's disease and mild cognitive impairment. Neurobiol. Aging 27, 1372-1384. doi: 10.1016/j.neurobiolaging.2005.09.012

Selkoe, D. J. (2002). Alzheimer's disease is a synaptic failure. Science 298, 789-791. doi: $10.1126 /$ science. 1074069

Serrano-Pozo, A., Frosch, M. P., Masliah, E., and Hyman, B. T. (2011). Neuropathological alterations in Alzheimer disease. Cold Spring Harb. Perspect. Med. 2011:a006189. doi: 10.1101/cshperspect.a006189

Shinohara, M., Petersen, R. C., Dickson, D. W., and Bu, G. (2013). Brain regional correlation of amyloid- $\beta$ with synapses and apolipoprotein $\mathrm{E}$ in non-demented individuals: potential mechanisms underlying regional vulnerability to amyloid- $\beta$ accumulation. Acta Neuropathol. 125, 535-547. doi: 10.1007/s00401-013-1086-9

Strittmatter, W. J., Saunders, A. M., Schmechel, D., Pericak-Vance, M., Enghild, J., Salvesen, G. S., et al. (1993). Apolipoprotein E: high-avidity binding to beta-amyloid and increased frequency of type 4 allele in late-onset familial Alzheimer disease. Proc. Natl. Acad. Sci. U.S.A. 90, 1977-1981. doi: 10.1073/pnas.90.5.1977

Terry, R. D., Masliah, E., Salmon, D. P., Butters, N., DeTeresa, R., Hill, R., et al. (1991). Physical basis of cognitive alterations in Alzheimer's disease: synapse loss is the major correlate of cognitive impairment. Ann. Neurol 30, 572-580. doi: 10.1002/ana.410300410

Tuminello, E. R., and Han, S. D. (2011). The apolipoprotein e antagonistic pleiotropy hypothesis: review and recommendations. Int. J. Alzheimers Dis. 2011:726197. doi: $10.4061 / 2011 / 726197$

Conflict of Interest: The authors declare that the research was conducted in the absence of any commercial or financial relationships that could be construed as a potential conflict of interest.

Copyright $\odot 2020$ Dzianok and Kublik. This is an open-access article distributed under the terms of the Creative Commons Attribution License (CC BY). The use, distribution or reproduction in other forums is permitted, provided the original author(s) and the copyright owner(s) are credited and that the original publication in this journal is cited, in accordance with accepted academic practice. No use, distribution or reproduction is permitted which does not comply with these terms. 